\title{
Environmental hazard of soil contamination by heavy metals
}

\author{
Saniia Efremova, Ekaterina Parfenova ${ }^{*}$, and Aleksei Bodrov \\ Penza State Technological University, Baydukova Passage/Gagarina Str., 1a/11, 440039 Penza, \\ Russia
}

\begin{abstract}
Pollution of the natural environment of the city with heavy metals (HM) from various sources receives much attention. They accumulate, exceeding the background level, cause pollution of the surface of the soil cover, vegetation, natural waters. It should be noted that their accumulation turns soils into a source of secondary pollution of natural environments and poses a threat to human health. In this regard, the monitoring studies, in addition to the traditional control of the HM content in soils, should assess the trend of changes in the level of pollution and their consequences. The object of research is soils, subject to varying degrees of anthropogenic burden. The analysis revealed a significant variation in all studied elements, which indicates a negative trend of their gradual increase. The average content of HMs was found not extreme but the rate of their accumulation raises concerns. An excess of MPC was found along highways (up to $500 \mathrm{~m}$ ), from the railway (up to $20 \mathrm{~m}$ ): $\mathrm{Pb}$ by $1.25-3$ times; $\mathrm{Cd}-1.65$; $\mathrm{Ni}-1.69-1.81$; on the adjacent territory to the gas station by 1.37 times for copper, and 3.45 times for lead, which indicates the danger of pollution of the urban environment.
\end{abstract}

\section{Introduction}

Environmental pollution as a result of economic activity gradually leads to a deterioration of the ecological component of the urban environment and endangers humanity.

Contamination of the natural environment with heavy metals (HMs) from various sources receives much attention; they accumulate, exceeding the background level of content in soils $[1,2,3,4]$.

Emission of gases, smoke in the form of technogenic dust introduced HM into the atmospheric air. Even in small quantities, their constant emission can gradually lead to accumulation in the soil $[5,6,7,8,9]$. Gas and dust emissions into the atmosphere, creating streams of toxic substances, cause contamination of the surface of the soil cover and vegetation. At the same time, soils, as a biogeochemical barrier, absorb pollutants and purify natural environments (water, air). At the same time, plant production even from slightly contaminated soils will lead to a gradual increase in HM in a living organism [10, $11,12]$. Also, their accumulation turns soil into a source of secondary pollution of atmospheric air, water, vegetation and poses a threat to human health. 
In this regard, the monitoring studies, in addition to the traditional control of the HM content in soils, require assessing the trend of changes in the level of pollution and their consequences.

\section{Materials and Methods}

The main object of research was the soil cover, which, to varying degrees, is subject to pollution on natural and man-made landscapes of the territories of the city of Penza and its region. The sampling sites were determined according to Methodological guidelines 2.1.7.730-99. In the course of the study, the analysis of monitoring materials for atmospheric air and soils and the study of the reaction of soils to man-made pollution were also carried out.

Mobile and bulk forms of HM in soil samples were identified based on the source of pollution and the distance to it. The results were compared with the background values of samples of uncontaminated soil - gray forest soil of the same granulometric composition, with approximately the same humus content (2.2-2.8\%), $\mathrm{pH} \mathrm{KCl} \mathrm{(5.1-5.25),} \mathrm{located} 20 \mathrm{~km}$ from the research sites (territory of Akhunsky forestry).

The analyses were performed in triplicates. The research and analysis used the generally accepted methods: determination of gross forms of heavy metals in $1.0 \mathrm{~N} \mathrm{HCl}$ using Spectrum-5-1 and AAS atomic absorption spectrophotometers; determination of mobile forms of $\mathrm{Pb}$ and $\mathrm{Cd}$ in an acetate-ammonium extract with a $\mathrm{pH}$ of 4.8 according to $\mathrm{RD}$ 52.18.191-89. Statistical processing of the experimental data was carried out with the use of correlation and regression analysis in Excel and Statistica 7.0.

\section{Results and Discussion}

The increasing anthropogenic burden on natural areas is inextricably linked with the country's economic growth. Transport is known as the main source of environmental pollution besides industry. As a result of the constant entry of pollutants into the environment, even in small quantities, $\mathrm{HM}$ accumulate in the soil $[5,6,7]$.

The state and contamination of soils can be assessed if there is information on the natural concentrations of HMs in soils and plants. On the basis of the same data, further measures ca be taken to preserve soil fertility and improve the quality of crop production. The assessment of the level of soil contamination by the content of HMs should consider the fact that, at present, the levels of maximum permissible contents of HMs, used to standardize the quality of soils, cause many discussions and questions. Despite the fact that MPCs for all soils are equal in Russia as a whole, many authors also note the need for their correction in respect to various soil properties (humus content, particle size distribution, acidity, etc.).

Often a question arises as to which of the proposed values of the MPC levels to use, as their use causes certain problems if the conditions of specific soils are neglected. At the same time, there are opinions that it is more expedient to carry out rationing according to the maximum concentrations established for a group of plant crops, which differ in their protective capabilities from HM ions, rather than for individual soils.

Knowing the peculiarities of HM consumption by plants, in particular, that many plants among all known elements assimilate cadmium most intensively, V.B. Iliin [13] recommends correcting the MPC downward for $\mathrm{Cd}$ and upward for $\mathrm{Pb}$ (and partly for $\mathrm{Zn}$ ).

The analysis of the results of the study of the content of $\mathrm{HM}(\mathrm{Mn}, \mathrm{Pb}, \mathrm{Zn}, \mathrm{Cu}, \mathrm{Hg}, \mathrm{Cd}$, $\mathrm{Ni}, \mathrm{Cr}$ ) in soils for 1990-1999 [14, 15] showed a significant variation in the content of the studied HMs in the soils of the Penza region. The greatest variability is noted for zinc (its 
maximum content is 12.7 times higher than the minimum), and the least variability - for mercury (its maximum content is 1.8 times higher than the minimum) (Fig. 1). The ecological and toxicological assessment of the arable soils of the region as of 01.01.2000 revealed that the generally low and permissible total content of HMs.

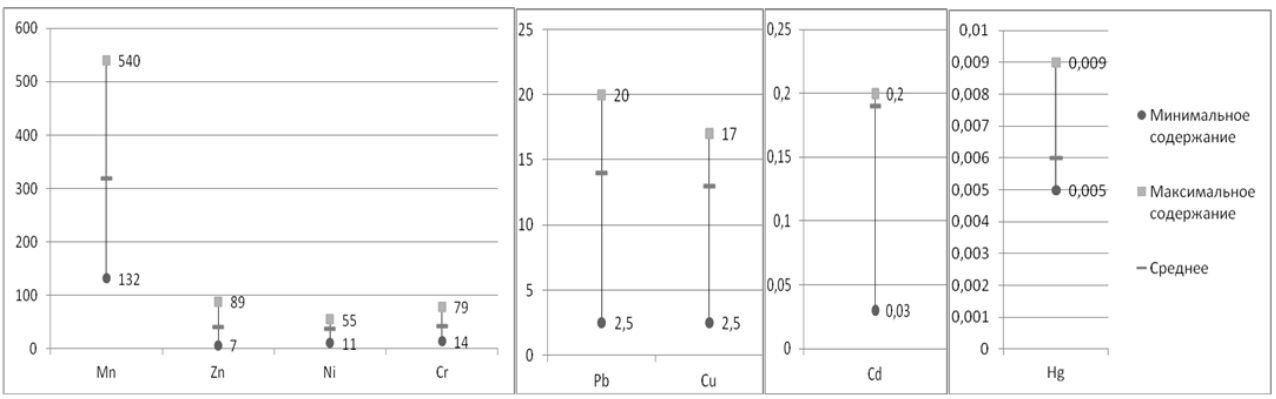

Fig.1. HM content in the soils of the region (1990-2000), $\mathrm{mg} / \mathrm{kg}$ soil

Where: минимальное содержание - minimum content; максимальное содержание - maximum content; среднее - average.

A negative trend in the change in the HM content was revealed as a result of the analysis of the published data as of 01.01 .2010 and the materials of the agrochemical service center on 15 reference objects of soils of the region (Fig. 2). We can state an unfavorable ecological situation gradually developing in terms of the HM background contamination of soils in the region [16].

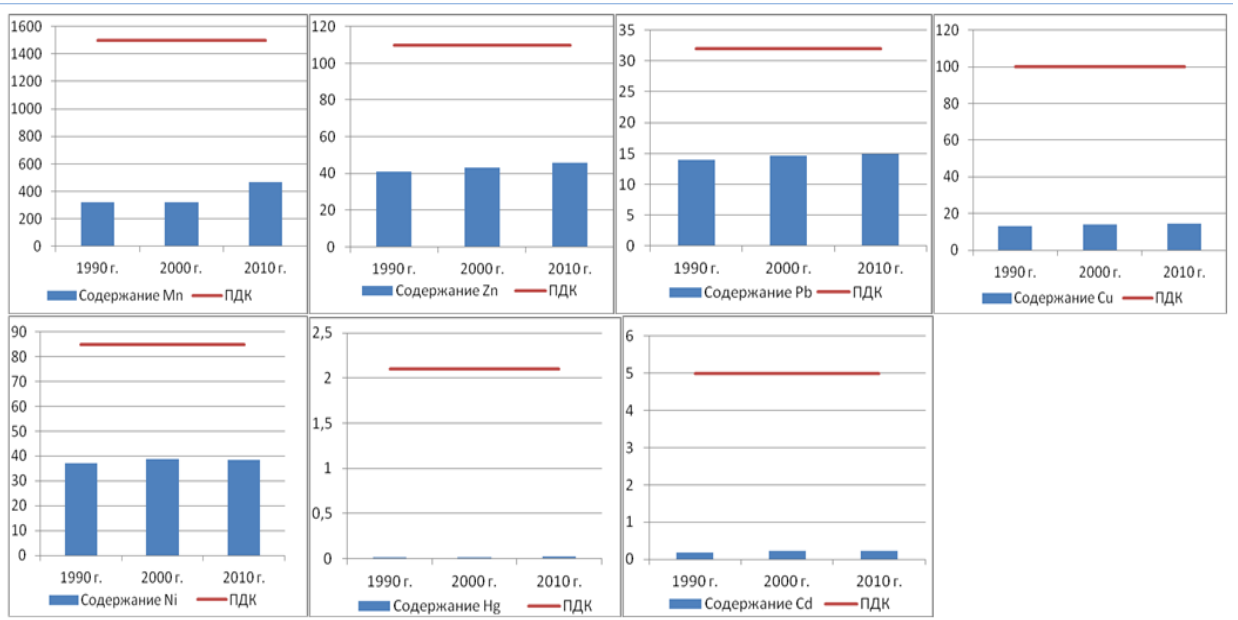

Fig. 2. HM content in the soils of the region (1990-2000), $\mathrm{mg} / \mathrm{kg}$ soil

Where: содержание - content; ПДК - МРС.

The polluting components are known to stay in the soil much longer than in other environments. At the same time, if we talk about soil contamination with HM, then this type of pollution is considered to be practically eternal. Despite the fact that the metals accumulated in the soil are removed during erosion and deflation, leaching, and consumption by plants, these processes are rather slow. [17]. Thus, various metals are characterized by highly variable and long half-removal periods: $70-510$ years for $\mathrm{Zn}, 13-$ 110 years for $\mathrm{Cd}, 310-1500$ years for $\mathrm{Cu}$, and 740-5900 years for $\mathrm{Pb}$. 
In some cases, local pollution may take place, exceeding the background values by 5-10 times. Thus, copper and mercury can cause slight pollution, and lead and nickel, the content of which in some samples exceeds the MPC standards, cause severe pollution. If, in general, the average content of heavy metals in soils is estimated, then it, of course, is not extremely dangerous or extreme, but rather the rate of HM accumulation gives rise to great concern. With the established excess of the background concentrations for $\mathrm{Zn}, \mathrm{Mn}, \mathrm{Hg}, \mathrm{Pb}$, $\mathrm{Cu}$, the danger often lies precisely in the fact that, as a rule, several HMs accumulate in the soil at once, i.e. the so-called polymetallic accumulation.

We should note that, despite the increased level of anthropogenic impact on the soil cover, the state of knowledge regarding soil pollution with heavy metals in the region remains low.

As a result of emissions from vehicles and industrial facilities, the most dangerous pollutants in their composition are lead, cadmium, and zinc, belonging to the first hazard class. The penetration of these HMs into the soil leads to their gradual accumulation, and with their constant supply, even in small quantities, to their concentration.

Along the federal and regional highways, transport soil pollution is formed leading to a kind of abnormalities [18]. The exhaust gases of vehicles are the main sources of massive lead pollution, tire wear - zinc pollution, diesel engines - cadmium. The studies of soil cover revealed that some of the studied elements had values within and below the permissible concentrations (Fig. 3), and the excess of the MPC was noted in the immediate vicinity of the road: up to 3 times for copper, up to 1.55 times for nickel, and insignificantly for lead and cadmium - 1.1 times.

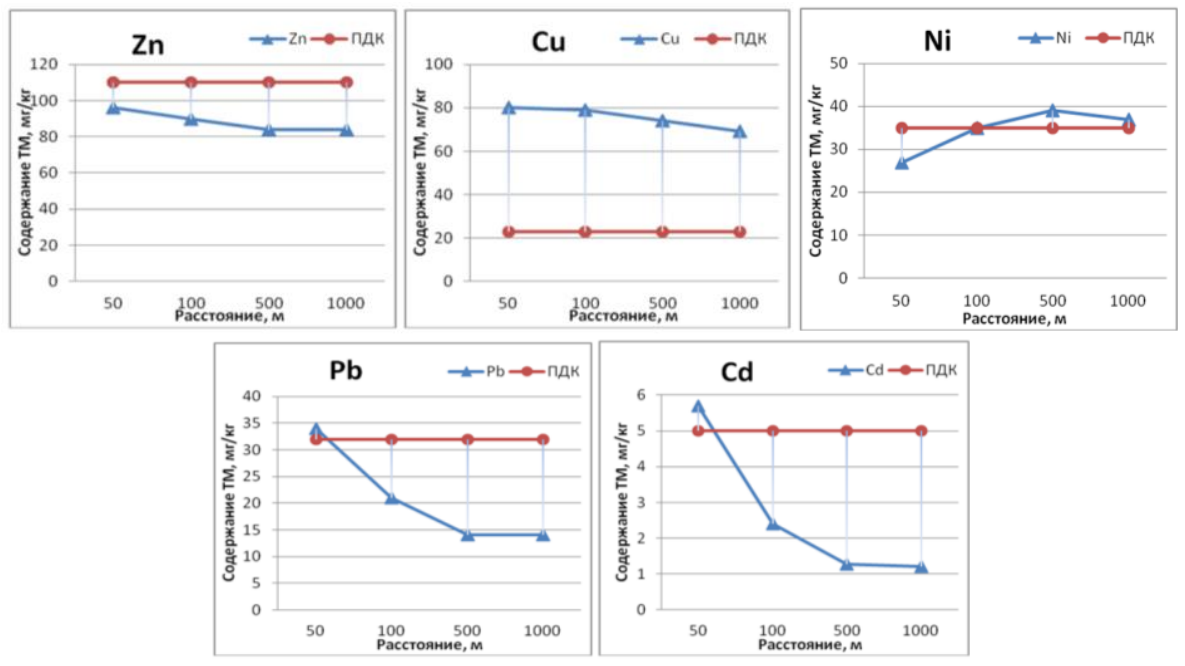

Fig. 3. HM content in the highway soil ( $\mathrm{mg} / \mathrm{kg}$ soil)

Where: содержание ТМ, мг/кг. - НM content, mg/kg; расстояние, м - distance, m; ПДК - МРС.

The location of petrol stations within the city is no less dangerous in terms of soil pollution [19]. In this regard, samples were taken from the territory adjacent to the gas station. The analysis of the selected soil samples (Fig. 4) showed an excess of the MPC for the content of mobile forms of $\mathrm{Pb}-3.45$ times, $\mathrm{Cu}-1.37$ times, while zinc was within the MPC. 


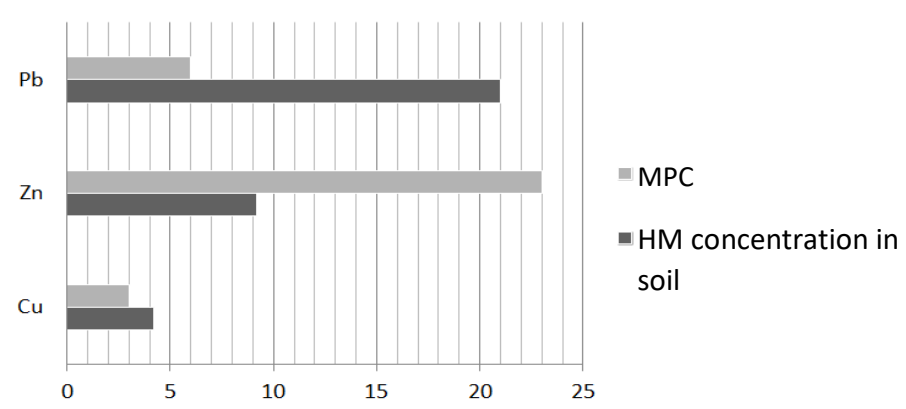

$\mathrm{HM}$ content, $\mathrm{mg} / \mathrm{kg}$

Fig. 4. HM content in the petrol station soil ( $\mathrm{mg} / \mathrm{kg}$ soil)

Rail transport, in turn, also makes a significant contribution to environmental pollution, often running through the city $[20,21]$. The study of the influence of railway transport showed an increased content of $\mathrm{Zn}, \mathrm{Cu}, \mathrm{Pb}, \mathrm{Cd}$ and $\mathrm{Ni}$ 5-20 m from the track (in a layer of $0-15 \mathrm{~cm}$ ). The excess of MPC was established for cadmium - 1.6 - 6.6; lead - 1.4 - 3.0; zinc - 1.8; copper -1.4-1.9; and nickel - 1.8 times (Fig. 5).

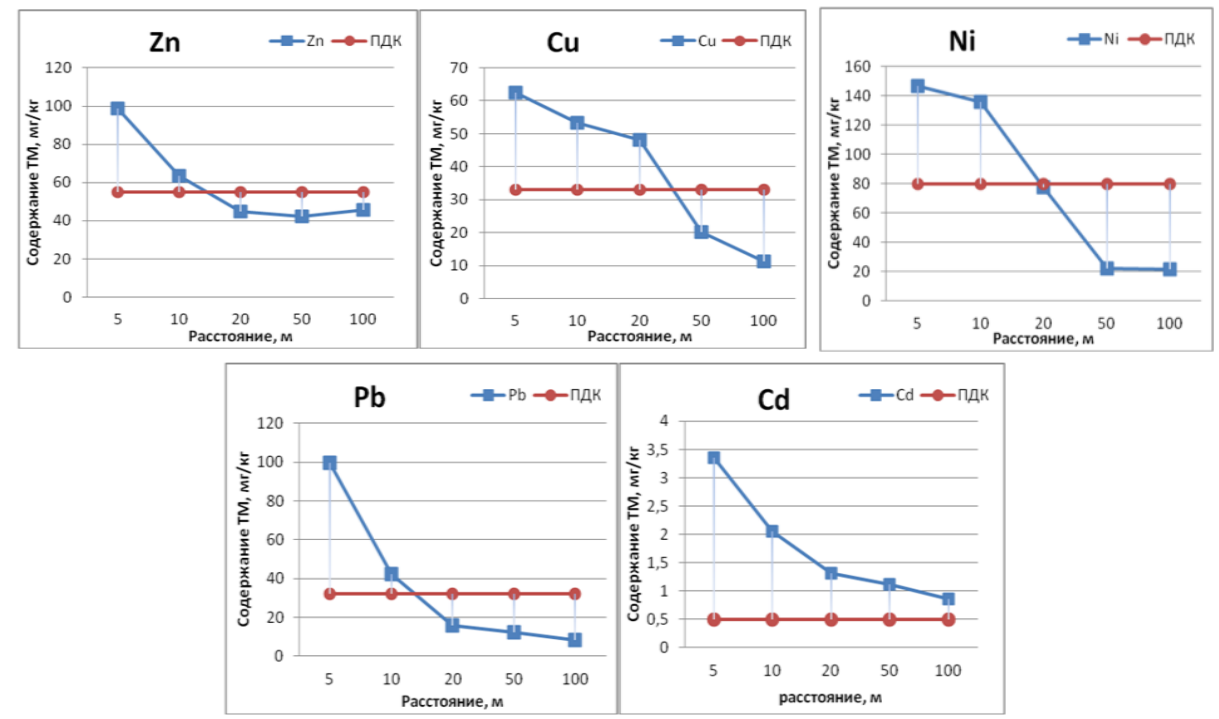

Fig. 5. HM content in the railroad bed soil ( $\mathrm{mg} / \mathrm{kg}$ soil)

Where: содержание ТМ, мг/кг. - НM content, mg/kg; расстояние, м - distance, m; ПДК - МРС.

The presented data are consistent with the results obtained by foreign researchers. For example, in Pakistan, a qualitative and quantitative assessment of lead contamination of soil along two major roadsides (the M-2 and the N-5 national highway) at Thokar Niaz Baig (TNB) in Lahore showed that lead comes mainly from automobile emissions, which could lead to to an increase in the level of lead in the vegetation of associated areas. It also provides a comparison of the concentrations of heavy metals $(\mathrm{Pb}, \mathrm{Cu}, \mathrm{Cd}, \mathrm{Zn}, \mathrm{Ni}, \mathrm{Fe}, \mathrm{Mn}$, $\mathrm{Cr}, \mathrm{Ti}$ ) in different regions of Pakistan and their adverse effects on plant growth [22].

In turn, the results of a study of the industrial zone of Hawassa (Ethiopia) also indicate a strong pollution of soils with heavy metals [23]. The concentration of heavy metals in the studied sites in Korea did not exceed Korean standards; the geoaccumulation index of each 
soil indicated that the degree of $\mathrm{Cd}, \mathrm{Cu}$, and $\mathrm{Pb}$ contamination was severe or extremely serious in more than twenty of the studied soil samples. The increase in the content of heavy metals in the soil in the immediate vicinity of industrial facilities is of concern and should be considered in the future management of agricultural soils around such complexes, as well as in the operation of the complex itself [24].

\section{Conclusions}

Thus, based on the presented data of our studies we can conclude that the gray forest soils of the forest-steppe of the Middle Volga region vary significantly in the content of heavy metals. As a result of the analysis of the data obtained, an increased content and excess of the MPC of heavy metals in the top fertile layer was revealed, which has a negative impact on the soil cover and creates an unfavorable ecological situation in these territories.

The established pollution (above the MPC) along highways at a distance of up to $500 \mathrm{~m}$, from the railway at a distance of up to $20 \mathrm{~m}$ - for $\mathrm{Pb}$ at $1.25-3$; $\mathrm{Cd}-1.65$; $\mathrm{Ni}-1.69-1.81$ times; the adjacent territory to gas stations by 1.37 times for copper, and 3.45 times for lead, indicates the danger of environmental pollution in the city.

\section{References}

1. V.B. Iliin, A.I. Sysova, Trace elements and heavy metals in soils and plants (2001)

2. S.Iu. Sharkova, Potatoes and vegetables, 8 (2008)

3. S.Iu. Sharkova, Ecological state of natural and man-made ecosystems of the Middle Volga region and their rehabilitation: author's abstract (2010)

4. E.A. Parfenova, Ecological assessment of gray forest soils in the Middle Volga region under anthropogenic load: author's abstract (2012)

5. S.Kh. Dzanogov, Heavy metals in the soils of North Ossetia - Alania (2001)

6. I. N. Zakharov, Content of heavy metals as one of the criteria for chemical soil degradation (2002)

7. V.I. Titova, M.V. Dabakhov, Features of the accumulation and distribution of heavy metals in the soil cover of an industrial city (2002)

8. S.A. Tobratov, Features of migration and accumulation of heavy metals in the soils of the impact zone of a large industrial facility (2002)

9. S.Iu. Sharkova, E.V. Nadezhkina, Soil fertility, 4 (37) (2007).

10. M.M. Ovcharenko, Heavy metals in the soil - plant - fertilizer system (1997)

11. V.V. Dobrovolskii, Geography of trace elements and global dispersion (1983)

12. S.Iu. Sharkova, E.V. Nadezhkina, Agro-XXI Vek - scientific-practical journal, 10-12 (2009)

13. V.B. Iliin, Heavy metals in the soil-plant system (1991)

14. A.P. Karpov, Report on research and production activities of Penzenskii State Center of Agrochemical Service for 1990-1992 (1992)

15. A.P. Karpov, Report on the research and production activities of Penzenskii FSUE AS for 2000 (2000)

16. L.V. Mosina, E.A. Dovletiarova, S.Iu. Efremova, Zh. Norvosuren, News of V.G. Belinsky Penza State Pedagogical University, 29 (2012)

17. A. Kabata-Pendias, Kh. Pendias., Trace elements in soils and plants (1989)

18. E.A. Parfenova, News of V.G. Belinsky Penza State Pedagogical University, 25 (2011)

19. E.A. Poianskova, E.A. Parfenova, S.Iu. Sharkova, XXI century: results of the past and problems of the present plus, 1 (01) (2011) 
20. M.A. Zhuravleva, N.I. Zubrev, M.I. Panfilova, O.V. Novoselova, S.Yu. Efremova Ecology and Industry of Russia, 22(9) (2018)

21. M.A. Zhuravleva, N.I. Zubrev, M.I. Panfilova, S.Yu. Efremova, Ecology and Industry of Russia, 22 (2) (2018)

22. Asrar Ahmad, Shabbir Hussain, Sajid Mahmood Rao, Amina Asghar, Misbah Irshad, Muhammad Aslam, Syed Salman Shafqat, Mohsin Javed, Muhammad Shahzad Bashir, Hafiza Samreen Kausar, Pol. J. Environ. Stud., 29(4) (2020)

23. B. Samuel, S. Solomon, F. Daniel, GM. Zinabu, G. Riise, J. Appl. Sci. Environ. Manage, 24(8) (2020)

24. Hyunuk Kim, Mina Lee, Jae-Hwang Lee, Kye-Hoon Kim, Gary Owens and Kwon-Rae Kim., Kim et al. Appl Biol Chem (2020) 